\title{
"Warning" to postoperative complications when using hemostatic agents!
}

\author{
Shadi Al-Afif ${ }^{1}$ (D) Joachim K. Krauss ${ }^{1}$
}

Received: 21 February 2019 / Accepted: 22 February 2019 / Published online: 15 March 2019

(C) Springer-Verlag GmbH Austria, part of Springer Nature 2019

Dear Editor,

We appreciate the interest of Dr. Franceschini and colleagues in our recent manuscript published in this journal [1]. This group has alerted the medical community about possible complications after using oxidized regenerated cellulose in breast surgery [2-4]. They described a relatively high incidence of foreign body reactions associated with this substance when used in breast surgery and also strategies to minimize surgical risk. They rightfully indicate that surgeons should mention in their operative report which biomaterial has been used during surgery for hemostasis. To our opinion, it is of course best to be as restrictive as possible with such agents. We as neurosurgeons embrace the exchange of clinical experience between different surgical disciplines to improve the prevention and management of such unexpected findings.

This article is part of the Topical Collection on Neurosurgery general

Shadi Al-Afif

al-afif.shadi@mh-hannover.de

1 Department of Neurosurgery, Hannover Medical School, Carl-Neuberg Str. 1, 30625 Hannover, Germany

\section{References}

1. Al-Afif S, Hatipoglu Majernik G, Hermann EJ, Esmaeilzadeh M, Hartmann C, Krauss JK (2018) Intracranial foreign material granulomas after cranial surgery. Acta Neurochir 160(11):2069-2075

2. Franceschini G, Sanchez AM, Visconti G, Di Leone A, D'Archi S, Mulè A, Santoro A, Salgarello M, Masetti R (2016) Reduction mammoplasty using oxidized regenerated cellulose as a filler in breast conservation surgery. Ann Ital Chir 87:292-297

3. Franceschini G, Visconti G, Sanchez AM, Di Leone A, Salgarello M, Masetti R (2015) Oxidized regenerated cellulose in breast surgery: experimental model. J Surg Res 198(1):237-244

4. Franceschini G, Visconti G, Terribile D, Fabbri C, Magno S, Di Leone A, Salgarello M, Masetti R (2012) The role of oxidized regenerate cellulose to prevent cosmetic defects in oncoplastic breast surgery. Eur Rev Med Pharmacol Sci 16(7):966-971

Publisher's note Springer Nature remains neutral with regard to jurisdictional claims in published maps and institutional affiliations. 